\title{
Hospitalidade como expressão do cuidado em enfermagem
}

\author{
Hospitality as an expression of nursing care \\ Hospitalidad como expresión de la atención de enfermería
}

\section{Daniela Couto Carvalho Barra', Roberta Waterkemper", Silvana Silveira Kempfer"I", Telma Elisa Carraro"II, Vera Radünz ${ }^{\text {III }}$}

'Universidade Federal de Santa Catarina. Programa de Pós-Graduação em Enfermagem.

Grupo de Pesquisa em Tecnologias, Informações e Informática em Saúde e Enfermagem. Florianópolis, SC

"Universidade Federal de Santa Catarina. Programa de Pós-Graduação em Enfermagem.

Grupo de Pesquisa em Educação em Enfermagem e Saúde. Florianópolis, SC

II'Universidade Federal de Santa Catarina. Departamento de Enfermagem. Grupo de Pesquisa Cuidando e Confortando. Florianópolis, SC

\section{Submissão: 12/12/2008 Aprovação: 15/01/2010}

\section{RESUMO}

Pesquisa Qualitativa com objetivo de refletir e discutir a relação existente entre hospitalidade, cuidado e enfermagem sob o olhar e experiências de um grupo de pós-graduandas através do referencial da Hospitalidade enQuanto cuidado em Enfermagem. Foram realizados dois encontros teórico-práticos, no segundo semestre de 2008, na disciplina "O cuidado em Enfermagem e Saúde" do Programa de Pós-Graduação em Enfermagem, de uma universidade federal do Sul do Brasil. Na coleta de dados aplicou-se um instrumento semi-estruturado e para análise dos dados a análise de conteúdo de Bardin. No total participaram dez pós-graduandas. A Hospitalidade é imperativa para a adaptação dos indivíduos no contexto hospitalar ou em QualQuer área onde se realiza atendimento à saúde.

Descritores: Humanização da Assistência; Acolhimento, Educação em enfermagem.

\section{ABSTRACT}

Qualitative research whose purpose was to reflect and argue about the relationship between hospitality, care and nursing according to experiences of PhD students. The research was developed from theoretic and practical meeting carried through by disciplines "the care in Nursing and Health" of PhD nursing Program at Santa Catarina Federal University. Its chosen theoretical frame of Hospitality perspective while nursing care. Data were colleted applying a semi-structured Questionnaire at ten doctoral students. The analysis of the data was carried through under the perspective of the content analysis according to Bardin. Hospitality it is imperative for the individuals adaptation in the hospital context or any area where it is looking for health care.

Key words: Humanization of the assistance; User ambracement; Education, nursing.

\section{RESUMEN}

Es una investigación cualitativa Que buscó reflejar y discutir referente la relación existente entre la hospitalidad, el cuidado y enfermería en la visión de las experiencias del grupo de doutorandas. Fue desarrollada a través del disciplina "el cuidado en el oficio de enfermería y la salud" del programa después de la graduación en el oficio de enfermería de una universidad del sur de Brasil. La recogida de datos un cuestionario de la mitad-structuralized fue solicitado. Participaram de diez doutorandas. El análisis de los datos fue llevado a través bajo perspectiva del análisis del contenido de Bardin. La Hospitalidad es imprescindible para la adaptación de los individuos en el contexto del hospital o cualquier área donde si ella atención de los profisionales en salud.

Descriptores: Humanización de la Atención; Acogimiento; Educación en enfermería.

AUTOR CORRESPONDENTE Telma Elisa Carraro.Rua José Brognoli, I I 8 - apto. 403. CEP: 88045-520. Florianópolis, SC.

E-mail: telmacarraro@ccs.ufsc.br 


\section{INTRODUÇÃO}

O cuidado é uma característica fundamental da prática de Enfermagem. As enfermeiras como profissionais de Enfermagem, podem contribuir para Que a essência deste cuidado permaneça centrada na sensibilidade, na ciência e na arte, refletindo sobre o seu fazer e o conhecimento envolvido.

Considera-se que uma das formas Que a enfermagem tem para manifestar-se como ciência e arte seja através do cuidado, uma vez Que este é constituído por diversos elementos Que o caracterizam como o saber e o fazer da profissão(l).

$\mathrm{O}$ cuidado em enfermagem implica em auxiliar o ser humano a percorrer um caminho Que lhe dê a compreensão de Que a vida é repleta de sentidos e sentimentos, bem como fazer com Que as pessoas prolonguem ou renovem as formas de ser e sentir-se saudável(2).

Neste sentido, o cuidado em saúde e em enfermagem, seja ele individual ou coletivo, estabelece uma dinâmica intersubjetiva e, por vezes, imperceptível, entre o cuidador (enfermeira) e o ser cuidado (ser humano).

Refletir sobre o cuidado nos faz perceber Que cuidar de seres humanos implica ter intimidade, senti-los dentro de si mesmo, acolhê-los, respeitá-los, dar-lhes sossego e repouso. Cuidar é entrar em sintonia com, auscultar-lhes o ritmo e afinar-se com eles. Dessa forma, o ser humano consegue viver a experiência fundamental do valor, daquilo Que tem importância e definitivamente conta. Tudo começa com o sentimento, Que nos faz sensíveis ao Que está a nossa volta, Que nos faz gostar ou desgostar. É o sentimento Que nos une às coisas. Se formos capazes de sentir, podemos agir em prol da melhoria do eu e do outro ${ }^{(2)}$.

Em todas as suas dimensões, o cuidado provoca reflexões acerca de Questões axiomáticas como a convivência, a tolerância, o respeito, a hospitalidade, a ecologia, a espiritualidade do ser humano. Desta forma, configura-se em uma perspectiva complexa de interação e intenção humana no sentido de gerar reações dinâmicas em todos os envolvidos.

A hospitalidade pode ser entendida como uma das expressões do cuidado em saúde e enfermagem e percebida como um conjunto de características Qualificadas, humanizadas e acolhedoras por meios olhares abrangentes voltados para o ser humano.

Na construção da relação entre os profissionais de saúde e os seres humanos Que necessitam de cuidado, algumas particularidades destacam-se nas atitudes e nos comportamentos da Hospitalidade em saúde e enfermagem, entre elas: a boa vontade incondicional, a acolhida generosa, a escuta atenciosa, o diálogo franco, o negociar honesto, a renúncia desinteressada, a responsabilidade consciente e a relativização corajosa ${ }^{(3)}$.

A Hospitalidade como parte do cuidado, pode representar um meio de cuidar do outro e cuidar de si, e estabelece uma relação de integração e interação mútua. Esta relação de convivência, entendida como a capacidade de fazer conviver as dimensões de produção e de cuidado, de efetividade e de compaixão; a modelagem de tudo o que produzimos usando a criatividade, a liberdade e fantasia, caracterizando-se como uma mútua pertença ${ }^{(4)}$.

Esta convivência pode ser exercitada dinamicamente por meio da hospitalidade. A partir destas considerações este estudo tem por objetivo refletir acerca da relação existente entre hospitalidade, cuidado e enfermagem a partir do olhar e das experiências de enfermeiras pós-graduandas.

\section{MÉTODOS}

Este estudo foi desenvolvido a partir de encontros teóricopráticos realizados na disciplina "O cuidado em Enfermagem e Saúde" do Programa de Pós- Graduação em Enfermagem, em uma Universidade Federal do Sul do Brasil, no segundo semestre de 2008. Trata-se de uma pesquisa do tipo exploratório-descritiva com abordagem Qualitativa, a Qual busca uma compreensão mais ampla da realidade estudada ${ }^{(5)}$. Participaram do estudo dez pósgraduandas, sendo nove enfermeiras e uma fisioterapeuta mediante o preenchimento do Termo de Consentimento Livre e Esclarecido (TCLE), conforme determina a resolução número 196/96 do Conselho Nacional de Saúde. Por se tratar de um estudo Que envolveu a participação de seres humanos foram também adotados os procedimentos explicitados na Declaração de Helsinki e os cinco referencias básicos da Bioética, Quais sejam: autonomia, nãomaleficência, beneficência, justiça e anonimato. Neste sentido, os participantes do estudo foram identificados pelas seguintes siglas: Pós-Graduanda (PG1, PG2, e assim sucessivamente).

O projeto de pesquisa foi aprovado pelo Comitê de Ética da Universidade Federal de Santa Catarina (UFSC) sob o número 407/ 08. Utilizou-se como ferramenta de coleta de dados um Questionário semi-estruturado possibilitando identificar os diferentes olhares e experiências acerca da Hospitalidade na saúde, na Enfermagem, no cuidado e entre os seres humanos. Este foi entregue às alunas após a realização de dois momentos durante o encontro Quinzenal da disciplina Que serviram de incentivo ao processo de discussão e reflexão sobre o tema "Hospitalidade".

Os dados foram analisados Qualitativamente por meio da técnica de análise de conteúdo de Bardin. A análise de conteúdo está fundamentada no Que está escrito, falado, mapeado e figurativamente desenhado e/ou simbolicamente explicitado e sempre será o ponto de partida para a identificação do conteúdo manifesto seja ele explícito e/ou latente ${ }^{(6)}$.

A análise e a interpretação dos conteúdos obtidos nesta técnica enQuadram-se em etapas a serem seguidas e, para a efetivação do método, a contextualização deve ser considerada como um dos principais requisitos ${ }^{(6)}$.

\section{RESULTADOS E DISCUSSÃO}

A partir da discussão realizada em sala de aula e após leitura e análise minuciosa dos Questionários, três categorias despontaram para análise: "Hospitalidade e Ser Humano", "Hospitalidade e Cuidado" e "Hospitalidade e Enfermagem".

\section{Hospitalidade e o Ser Humano}

Relacionar a Hospitalidade ao ser humano é um exercício reflexivo profundo Que resgata as formas de pensar e "ser hospitaleiro" destes, ao longo de sua evolução histórica. Mergulhando na origem gramática da palavra hospitalidade verifica-se Que em grego significa "philoxenos". Esta palavra origina-se pela junção de dois termos: phileo Que significa amar, ser amigo, mostrar afeição e "xenos" Que significa estrangeiro, estranho ${ }^{(7)}$. Através deste conceito e junção 
de termos é possível iniciar essa discussão compreendendo Que o ser humano é capaz de amar ao outro, mesmo o estranho, desde Que seja desnudado de preconceitos, fator hoje, decisivo na sua forma de ser e conviver em diferentes ambientes.

A hospitalidade é um ato de acolhimento entre seres humanos Que procuram ser recebidos entre si com atenção, amor e afeto de forma a sentirem-se bem e satisfeitos em uma inter-relação harmônica. Quando Questionados sobre o Que compreendiam sobre a hospitalidade, enquanto seres humanos, um dos sujeitos relatou Que a hospitalidade é:

"Interesse desinteressado por ajudar a outra pessoa" [...] é sinônimo de "Compaixão, no sentido não de lastima, e sim de comprometer-se com a pessoa, de torcer por seus interesses" (PG5)

Neste sentido, é possível verificar neste relato que a hospitalidade é uma atitude Que envolve o importar-se com o outro sem esperar algo em troca e realizar este comprometimento na intenção de proporcionar a satisfação e o bem-estar. É uma forma de:

"receber com atenção e dedicação Demonstrar cuidado com todos os detalhes para Que a pessoa sinta-se bem e confortável" (PG2)

Nesta relação de "hóspede-hospedeiro" há a necessidade de apresentar e desenvolver algumas atitudes como

\section{Atenção, Cuidado, Conforto, Sinceridade, Amor, Estar aberto para (PG6)}

Atitudes Que possibilitem manter uma relação de "acolhida", ou seja, como mencionado por (PG6) "estar aberto para". Esta abertura só pode ser alcançada a partir do momento em Que há nesta relação, a disponibilidade e a flexibilidade, assim como altruísmo e sentimentos como o afeto e o "Querer bem", como se evidencia, também, no relato de (PGI) e (PG7):

Senso altruísta, carinho e afeto (PGI)

\section{Disponibilidade e flexibilidade (PG7)}

Para os sujeitos deste estudo a relação de hospitalidade entre os seres humanos envolve satisfação, no sentido de sentir-se bem, e estar em relação e ao reconhecer o outro como humano reconhece as suas necessidades materiais, bens simbólicos e da existência de outro ser humano.

Para Que seja possível alcançar a satisfação desses três conjuntos de necessidades o ser humano desenvolve diferentes formas de interação e relacionamento afetivo, de elaboração de conhecimentos, de atividades lúdicas, bens e serviços ${ }^{(8)}$.

Entretanto, em virtude de sua própria evolução social, econômica e tecnológica a hospitalidade, característica peculiar do ser humano, acabou se diluindo e distanciando os seres humanos dessas relações e causando certa "xenofobia", Que significa a aversão a coisas ou pessoas estrangeiras ${ }^{(9)}$. Para algumas pós-graduandas a falta de hospitalidade pode ser observada no:
Sentimento de estranheza, distância, egocentrismo (PGI)

Egoísmo, mau humor e agressividade (PG7)

Hostilidade [...] (PG2)

Pressa, Olhar Biomédico, Rotinas Pré Estabelecidas (PG6)

Sentimentos e atitudes Que são direcionadas a outros seres humanos como nas relações entre: pais e filhos, casais, professor e aluno, chefe e empregado, sociedades de povos "diferentes", enfim, em todas as relações possíveis entre seres humanos nos seus diferentes contextos.

A discussão sobre "Hospitalidade" é uma das Questões Que está, atualmente, ganhando espaço e destaque nos meios de comunicação e em pesquisas, principalmente, na área hoteleira. Por este motivo estimula a pesQuisa sobre este tema tão simples e Que se tornou tão complexo ao mesmo tempo despertando a reflexão em diversos cenários.

A hospitalidade talvez seja um foco a ser trabalhado, e deveria ser condição básica para a sobrevivência de Qualquer empreendimento, principalmente daqueles cujo produto não é tangível e Que lida com pessoas. Neste caso a enfermagem é uma área a ser destacada e relacionada à hospitalidade, pois cuida do ser humano e ser hospitaleiro é uma atitude Que permeia o cuidado $^{(10)}$.

Com estes conceitos podemos compreender Que saber receber seus "hóspedes" significa a atenção Que se dá para os mesmos. A maneira de como nos relacionamos passa a ser mais importante Que o processo de trabalho em si. Saber operar máquinas e equipamentos também tem seu valor, mas não se deve valorizar esse aspecto em detrimento a Hospitalidade oferecida às pessoas ${ }^{(10)}$.

Entretanto, ser hospitaleiro deve ser um ato presente na vida cotidiana das pessoas, independente do ambiente em Que se encontre, ou seja, em casa, no trabalho, ou na rua. Apesar de alguns autores compreenderem a Hospitalidade e dividi-la em três âmbitos, o doméstico, o comercial e o público, o ser humano, por ser único, ter caráter, valores e formas de entender o mundo, não deve mudar seu modo de tratar as pessoas ${ }^{(1)}$.

Quando desprovida dos limites pré-estabelecidos nos conceitos de hospitalidade doméstica, comercial e pública, pode evidenciar o elemento humanizador no tratamento dispensado a QualQuer ser humano, como mostra PG5 em seu relato:

Desinteresse em estabelecer uma relação e em conhecer ao hóspede, lástima, falta de comunicação, pré-conceitos (PG5)

A partir desses depoimentos e conceitos é possível compreender a hospitalidade no campo da saúde e em particular, na Enfermagem cuja essência de trabalho é o cuidado.

\section{Hospitalidade e o Cuidado}

O cuidado é definido a partir da percepção individual e subjetiva de cada sujeito e traz consigo um olhar histórico e social, o Qual é construído pelas vivências, principalmente as vivências familiares. Podem-se considerar as relações maternas, a convivência com irmãos, primos, avós, dentre outros, como os "primeiros cuidados" 
Que se tem referência. Desta forma, pode ser observado como uma constituição ontológica, ligado a construção individual e coletiva de cada ser.

A abordagem filológica do cuidado traz um conceito referente ao sentido de cogitare-cogitarus, como sendo o mesmo de cura: cogitar, pensar, colocar atenção, mostrar interesse, revelar sua atitude de desvelo e de preocupação. ${ }^{(4)}$ Mas por outro lado, mantendo uma atitude de cuidado com tudo o que compreende a vida, pode antecipar-se aos problemas, evitando estados de desequilíbrio e manter a harmonia, considerando tal atitude como promoção da saúde.

Enquanto hóspedes, desfrutamos o que é oferecido e disponibilizado e como hospedeiro, colocamos à disposição o Que temos, para Que ambos em convivência possamos vivenciar momentos ímpares. A hospitalidade está relacionada ao acolhimento, ao deixar-se penetrar no íntimo, ao carinho e afeto, aos sentimentos mais puros Que se manifestam no outro e para o outro.

Quando Questionados sobre sua primeira referência de hospitalidade, os sujeitos do estudo referiram:

Quando li esta pergunta fiquei pensando em lembranças [...] e me veio à memória coisas da infância Quando minha mãe trocava o lençol da minha cama e eu deitava e sentia aquele cheirinho bom (PG2)

Quando criança ia de férias à casa de minhas avós e minhas tias, sempre fui bem recebida, com afeto, comida, etc (PG4).

A casa de minha avó, nas férias de final de ano, me sentia muito acolhida (PG5)

Minha primeira lembrança é de Quando passava férias na praia na casa de minha avó. (PG6)

Neste momento, os princípios do cuidado se misturam com os da Hospitalidade. Emergem destes depoimentos sensações e sentimentos como: carinho, afeto, bem estar, aconchego, família, cama, casa, lazer, dentre muitos outros Que nos remetem a situações de conforto e alegria.

O cenário pode ser a casa de um familiar ou a sua própria casa, mas o momento é que determina se a Hospitalidade traz boas ou más recordações.

Enfim, a primeira lembrança familiar de ser hóspede e Hospitalidade consolidam um gesto de cuidado, envolvendo a todos em um clima amigável, sereno e leve, onde cada um sente-se acolhido, sente-se bem e mesmo sem falar, Quer sempre voltar. Acolher é permitir, sob certas condições, a inclusão do outro no próprio espaço $^{(12)}$.

O hóspede pode vir em busca de auxílio, doente, em condições fragilizadas, o Que representa uma situação de cuidado. Presta atenção na movimentação, permite-se, aceita os deveres com alegria, inclusive aqueles que em seu cotidiano lhe causam desconforto. Os sujeitos do estudo descrevem as sensações/sentimentos ao ser hóspede/hospedado como:

Sentimentos de ser agradada, de ser cuidada com afeto e carinho, de amor (PGI)

Cama macia e gostosa, comida Quentinha e gostosa, um banho Quentinho (PG3)

Esta percepção do hóspede determina sua imagem e avaliação do local onde está hospedado, conforme as instalações, a comida, os objetos e utensílios dos Quais desfrutou, ele estabelece uma relação de intimidade ou não com o local.

De modo Quase intuitivo, o viajante, o turista ou o migrante, Quando chega a uma cidade e percorre os espaços onde se constroem essa forma urbana, é submetido a um sem-número de percepções, de situações e de processos importantes de informações ${ }^{(12)}$.

Outra Questão relatada é Quando o visitante permanece por um tempo mais prolongado eneuanto hóspede e passa a sentir saudades de casa, de seu mundo. Neste momento, a estadia tende a se transformar em experiência menos contemplativa e mais condicionada às rotinas do local onde está no momento. Como se percebe na fala de uma das entrevistadas:

De uma forma geral, tenho boas recordações Quando penso nesta Questão, mas por mais bem recebida, acolhida Que já tenha sido após um determinado tempo começo a ficar cansada e desejosa de retornar para meu ambiente (PG5)

A hospitalidade é, portanto, uma relação espacializada entre dois atores: aquele que recebe e aquele Que é recebido; ela se refere à relação entre um, ou mais hóspedes, e uma instituição, uma organização social, isto é, uma organização integrada em um sistema ${ }^{(12)}$. Nem sempre a rotina do local onde o hóspede está aproxima-se daquela ao qual está habituado em seu cotidiano. Como refere a entrevistada:

Me sentia acolhida porém devia seguir as regras da casa, Que eram diferentes da minha (PG6)

A hospitalidade pressupõe a entrada, a inclusão daquele hóspede em um sistema organizado como modalidade de funcionamento já existente $^{(12)}$. Em determinadas situações, o hóspede tem dificuldades em adaptar-se à realidade do contexto onde está hospedado. Por outro lado, Quem hospeda sempre procura oferecer o Que tem de melhor ao hóspede, Quer acolhê-lo com alegria e tenta manter um ambiente agradável. Ao abordar os sujeitos do estudo Quanto às sensações/sentimentos Que tiveram ao hospedar alguém, todos manifestaram interesse em deixar o hóspede à vontade, preocupando-se com o ambiente, com a comida, com os momentos de diálogo, como podemos perceber nas falas:

Ah, sempre Que recebo alguém dou o meu melhor para Que essa pessoa sinta-se querida e agraciada por meio de uma boa comida, por meio de uma boa conversa em um clima harmonioso (PGI)

Quando se estabelece um diálogo franco, há uma aproximação das pessoas, começa então a ocorrer um contato mais íntimo, um momento especial de integração de culturas, uma troca de experiências e vivências. Por isto, dialogar é entrar em reciprocidade 
e intercambiar ${ }^{(3)}$.

Outra expressão citada pelos sujeitos é a preocupação com a manutenção deste ambiente acolhedor, como se percebe nesta fala:

Preocupação para acolher da melhor maneira possível... se estava confortável e bem (PG2)

A acolhida não deve ser vivida como uma condenação porQue não temos outra saída. Devemos viver a acolhida jovialmente como Quem vê no outro um próximo, um companheiro de caminhada, um irmão e uma irma $\tilde{a}^{(3)}$. Esta acolhida deve ser demonstrada com alegria, satisfação e bem Querer, como se percebe nas falas:

Senti alegria pois Quando percebo Que alguém fica em minha casa é por que se sente bem aqui (PG3)

Interesse pela pessoa, satisfação, desejos de que a pessoa esteja bem confortável (PG4)

O ideal nunca se realiza totalmente. Nem é essa sua função. Sua função é alimentar o ânimo de sempre melhorar e de nos orientar na direção de práticas criativas Que superem as convencionais e rotineiras ${ }^{(3)}$. Porém, a busca pelo ideal Quando o desejo de receber alguém se transforma em preocupação, configurase em um momento de tensão e desequilíbrio, como se percebe nesta fala:

É uma constante preocupação em fazer a pessoa se sentir bem, "como se estivesse em casa", Que não lhe falte nada. (PG6)

A preocupação com o ideal em receber alguém faz com Que o anfitrião planeje a recepção, pensando em tudo, um verdadeiro preparo para Que tudo ocorra da melhor forma possível, o Que observamos na fala descrita por PG5:

É todo um preparo anterior e uma concentração de energias para que o "hóspede" sinta-se acolhido, integrante e integrado nesta situação. Acabo abrindo mão de alguns hábitos, rotinas na intenção de acolher o outro. Às vezes é cansativo e dependendo do "hóspede" pode ser frustrante, intenso (PG5)

O espírito de solidariedade humana e de parentesco com toda a vida é fortalecido Quando vivemos com reverência o mistério da existência, com gratidão pelo presente da vida, e com humildade considerando o lugar Que ocupa o ser humano na natureza ${ }^{(3)}$.

Sendo o cuidado a essência do trabalho da enfermagem e a hospitalidade uma atitude que demanda abertura pessoal e abrir mão de preferências, relaciona-se ainda ao Querer bem, ao acolhimento, a estar aberto, ao aconchego, ao gesto de dar carinho e afeto, entre inúmeras Qualificações, torna-se uma necessidade relacionar a hospitalidade com a enfermagem.

\section{Hospitalidade e a enfermagem}

A enfermagem como uma ciência, arte e profissão cujo objeto de cuidado é o ser humano apresenta como responsabilidade moral e ética promover a hospitalidade como forma de expressão de sua própria essência que é o cuidar de seres humanos. Na Enfermagem, esta pode ser compreendida como uma:

[...] estratégia Que abre a porta para o encontro entre seres humanos e que permite que os momentos e relacionamentos de cuidado possam acontecer como objeto da enfermagem (PG5)

Uma estratégia Que pode ser expressa como cuidado em saúde e enfermagem e Que se inicia através do acolhimento do ser humano Que necessita do cuidado em si, estando este doente ou não. Ao chegar ao serviço de saúde este "ser" encontra um ambiente diferente da sua convivência, desconhecido e por vezes, hostil e frio e passa a ser hospedado nas dependências da instituição de saúde.

Neste sentido, algumas características como a sensibilidade, a compaixão pelo próximo, a acolhida, o convite para aproximar-se e entrar, são dimensões da Hospitalidade inerentes aos profissionais de saúde, em especial aos profissionais da Enfermagem, uma vez Que estes são os primeiros a receberem os pacientes Que necessitam de cuidado. Tais características, ao estarem presentes nos profissionais de saúde, podem facilitar o momento de interação entre o profissional-paciente.

As participantes do estudo ao serem Questionadas sobre o Que entendiam por hospitalidade na enfermagem revelaram Que esta expressão do cuidado está diretamente relacionada com "acolhimento", conforme observado nas seguintes falas:

[...] é acolhimento, é permitir Que o outro seja ele mesmo, sintase confortável e cuidado num momento (ou ambiente) Que não é o [...] dele (PG5)

É saber receber as pessoas, se dócil com as mesmas, fazer as pessoas sentirem-se bem em sua casa (PG3)

[...] é ser e estar aberto para receber, acompanhar, ouvir as pessoas. Preparar e se preparar para cuidar ou oferecer um ambiente receptivo (PG7)

A palavra acolhimento, na enfermagem, pode ser definida como posturas/condutas Que o profissional da saúde, em especial, os profissionais de Enfermagem devem desenvolver no sentido de compreender e sensibilizar-se com outro, atendendo suas necessidades e direcionando-as, Quando necessário, para outros locais do sistema de saúde capacitado para resolvê-las ${ }^{(13)}$.

Assim, "acolher" não significa essencialmente resolver por completo todos os problemas relatados pelo paciente, mas sim dispensar atenção na relação mediante a escuta sincera, a valorização das suas Queixas e identificação de suas necessidades ${ }^{(14)}$.

A construção do momento de interação/relação, ou seja, de acolhimento do enfermeiro com o paciente é dinâmico, marcado por intenções, competências e intersubjetividades ${ }^{(15)}$. Neste momento, a escuta e o diálogo deve estar presente para Que a interação entre o profissional e o paciente ocorra de forma genuína, estabelecendo-se assim, uma relação ${ }^{(14)}$.

Portanto, o acolhimento como integrante da hospitalidade, como expressão do cuidado, concretiza-se no servir ao outro, percebendoo nos seus gestos, falas e limitações. Para isso, torna-se fundamental Que os profissionais possuam afinidade e afetividade em relação ao 
paciente $^{(16)}$.

Hospedar alguém presume Que estejamos dispostos a dividir o Que temos com o outro, mesmo o outro sendo diferente vindo de outro lugar, de outra cultura, com outros costumes, de outra classe social ou país. O nosso hóspede passa ser o "estranho" que vem de longe, de diferentes localidades, culturas e ambientes sociais e Que assim como os outros hóspedes requer empatia, afeto, amor, ser ouvido, confortado, alimentado, receber confiança, ou seja, ser cuidado incondicionalmente.

A hospitalidade supõe a superação dos preconceitos e confiança Quase ingênua, mas indispensável para Que a hospitalidade e a convivência sejam verdadeiramente hospitalidade e convivência sem constrangimento ${ }^{(3)}$.

Ao Questionar as participantes sobre a relação da Hospitalidade com a Enfermagem verifica-se Que:

"o ser humano que precisa de cuidado, precisa antes de tudo ser acolhido, e a enfermagem podem fazer parte deste acolhimento de forma bem simples, pensar como gostaria de ser cuidado". Se cada Enfermeiro refletisse sobre isto, o cuidado seria mais hospitaleiro. (PG2)

Penso que para uma enfermagem que exerce o cuidado além da doença, é essencial ter entre suas características principais a hospitalidade e o cuidado ao ser humano. (PG6)

Então, para os sujeitos deste estudo a hospitalidade apresenta relação com a Enfermagem através do cuidado. Cuidar significa acolher através da inter-relação. Acolher como "eu" enquanto "cuidador" gostaria de ser cuidado.

\section{CONSIDERAÇÕES FINAIS}

Os profissionais de saúde devem ter no seu perfil a Hospitalidade, onde o cuidado e o interesse pela busca do bem-estar do ser cuidado sejam valorizados e representativos nos valores institucionais. O interesse pelas necessidades apresentadas por Quem recebe o cuidado, o "Querer bem", pode ser identificado nas relações construídas e desta forma, a hospitalidade assume sua face mais nobre na moral humana, a de costurar, sedimentar, vivificar o tecido social e colocar em marcha esse processo sem fim Que alimenta o vínculo humana $^{(17)}$.

As categorias analisadas surgiram, espontaneamente, durante as discussões em grupo e Que, assim como no encontro, várias respostas preenchidas no instrumento de coleta de dados, se entrelaçavam/complementavam entre as categorias.

Esta pesquisa aponta a Hospitalidade como um gesto de acolhimento, abertura, altruísmo, carinho e cuidado, ao mesmo tempo em Que, cada ser humano tem em sua casa, o cenário da hospitalidade, e tem em sua família o primeiro contato com esta dimensão da vida em comunidade.

Este estudo demonstrou que o ser humano é único em suas escolhas, mas Quando recebe alguém, não o faz somente em sua casa, recebe em sua vida, na medida em Que troca experiências convive com diferenças, busca Qualificar suas relações. Tal comportamento configura-se em prática de cuidado, de acolhimento, de interesse pelo outro.

Para a enfermagem este momento de hospedar, é único, pois em muitas situações, esta é a última experiência de Quem chegou, tornando-se, portanto, um momento único também para Quem se hospedou.

\section{REFERÊNCIAS}

I. Schaurich D, Crossetti MGO. O elemento dialógico no cuidado de enfermagem: um ensaio com base em Martin Buber. Esc Anna Nery Rev Enferm 2008; 12(3): 544-8.

2. Silva LWS, Francioni FF, Sena ELS, Carraro TE, Radünz V. O cuidado na perpectiva de Leonardo Boff, uma personalidade a ser (re)descoberta na enfermagem Rev Bras Enferm 2005; 58(4): 471-5.

3. Boff L. Virtudes para um outro mundo possível - Hospitalidade: direito e dever de todos. Petrópolis: Vozes; 2005.

4. Boff L. Saber cuidar: ética do humano - compaixão pela terra. Petrópolis: Vozes; 1999.

5. Minayo MCS. Pesquisa social: teoria, método, criatividade. Petrópolis: Vozes; 2007.

6. Puglisi ML, Franco B. Análise de conteúdo. Brasília: Líber Livro; 2005.

7. Loraschin C. A vontade de Deus é Que sejamos plenamente humanos. [citado em 02 dez 2008]. Disponível em: http:// www.pime.org.br/catequese/cateomjbicarapostdeus2.htm.

8. Praxedes, W. Reflexões sociológicas sobre a hospitalidade. Espaço Acadêmico 2004; 37. [citado em 02 jun 2006]. Disponível em: http://www.espacoacademico.com.br/037/ 37epraxedes.htm.

9. Ferreira A. Aurélio: o dicionário da língua portuguesa. $2^{\mathrm{a}}$ ed Curitiba: Editora Positivo; 2008.
10. Miranda CL. Hotelaria brasileira: hospitalidade como vantagem competitiva. In: IV Congresso Nacional de Excelência em Gestão. Responsabilidade Socioambiental das Organizações Brasileiras. 2008 jul 3 I-ago 2; Niterói (RI), Brasil, Rio de Janeiro: $\mathrm{ABH}$; 2008. p. 2-14.

I1. Camargo LOL. Hospitalidade. São Paulo: Aleph; 2004.

12. Grinover L. A hospitalidade, a cidade e o turismo. São Paulo: Aleph; 2007.

13. Ramos DD, Lima MADS. Acesso e acolhimento aos usuários em uma unidade de saúde de Porto Alegre, Rio Grande do Sul, Brasil. Cad Saúde Pública2003; 19(1): 27-34.

14. Schneider DG, Manschein AMM, Ausen MAB, Martins II, Albuquerque GL. Acolhimento ao paciente e família na unidade coronariana. Texto Contexto Enferm 2008; 17(1): 81-9.

15. Rossi FR, Lima MADS. Acolhimento: tecnologia leve nos processos gerenciais do enfermeiro. Rev Bras Enferm 2005; 58(3):305-10.

16. Gargiulo CA, Melo MCSC, Salimena AMO, Bara VMF, Souza IEO. Vivenciando o cotidiano do cuidado na percepção de enfermeiras oncológicas. Texto Contexto Enferm 2007; I6(4): 696-702.

17. Vervisti CF, Babinski LR. O papel social do turismo junto aos idosos asilados - um processo de humanização com responsabilidade. Caxias do Sul: UCS; 2006. 